\title{
POR QUE O PLURILINGÜISMO RESULTA ACCESIBLE
}

François Grin

Université de Genève 



\section{INTRODUCIÓN}

Hai vinte anos, un lingüista australiano chamado Nicholas Thieberger publicou na revista científica Multilingua un artigo de título provocador: «Language Maintenance: Why Bother» (Preservar as linguas: por que preocuparse?, 1990).

A pregunta suxerida por Thieberger segue a ser procedente hoxe en día porque encarna a idea, moi estendida, de que o plurilingüismo resulta incómodo e caro de máis, e, en última instancia, é «un luxo que non está ao noso alcance».

A forma de plurilingüismo á que me estou a referir é, por suposto, o plurilingüismo social, non o individual, pois en xeral este último non causa trastorno ningún. Así, a maior parte da sociedade está de acordo con que dominar dúas ou tres linguas, ou máis, é unha boa cousa, xa que un individuo plurilingüe pode interactuar cun maior número de persoas e, por veces, esas competencias lingüísticas supoñen unha vantaxe no mercado laboral. En consecuencia, o valor do plurilingüismo individual non provoca polémica; no entanto, o que si suscita un acalorado debate é o valor do plurilingüismo social (ao que aquí me referirei co seu equivalente, "diversidade lingüística»).

O feito de percibir que o plurilingüismo social, ou diversidade lingüística, constitúe un problema en por si está fondamente arraigado, como é sabido, malia a lexitimidade política e ideolóxica que adquiriu o plurilingüismo nos últimos anos (moi notablemente en Sudáfrica, onde se decidiu recoñecer once linguas oficiais).

Abofé que a pregunta de Thieberger, que poderiamos reformular destoutro xeito: «Plurilingüismo? Por que molestarse?», é retórica. O que el pretendía era criticar a insensibilidade de moitos comentaristas ao rexeitaren o esforzo con que un gran número de países de todo o mundo pretenden preservar a diversidade lingüística (por non falar de como eses comentaristas menosprezan a promoción desta diversidade). Con todo, detrás desta clase de preguntas latexan problemas 
científicos totalmente lexítimos, pois non se pode dar por feito que resulte pertinente fomentar o plurilingüismo social.

Esta cuestión reviste maior complexidade do que parece. Neste relatorio vou tratar de estudar o problema de xeito analítico con miras a eludir determinadas argumentacións que se oen a miúdo e, no canto destas, propor unha perspectiva fundamentada en principios básicos da análise económica.

Primeiramente, vou tentar diferenciar catro niveis neste problema, a saber: o argumento moral ou referido aos «dereitos», o argumento da «viabilidade», o argumento da «asignación de recursos» e o argumento da «distribución dos recursos».

A seguir, tratarei de analizar en maior detalle o terceiro destes, é dicir, a asignación de recursos, problema económico por antonomasia, que resulta de vital importancia para podermos recoller a luva que nos guinda a pregunta de Thieberger. Ao así facermos, desviarémonos do camiño principal para introducirmos unha distinción fundamental: a que existe entre o plurilingüismo absoluto e o continxente.

Por último, intentarei pasar duns principios xerais aos custos reais e cuantificables que comporta o plurilingüismo para demostrar que, polo xeral, son baixos. De aquí se deriva a suposición, moi fundamentada, de que mesmo desde unha perspectiva puramente económica o plurilingüismo non supón tanto luxo... e, ao cabo, ben paga a pena o esforzo.

\section{CATRO DEBATES}

Supoñamos que estamos a manter unha acalorada discusión cunha persoa que afirma que está totalmente en contra do plurilingüismo e que pregunta, precisamente: «Por que preocuparse?».

Mais, atención, porque esta interrogante pode ter significados un tanto diferentes; caractericémolos primeiro brevemente, antes de pasarmos a examinalos máis a fondo.

- En primeiro lugar, se unha persoa rexeita o plurilingüismo, se non o considera un obxectivo social que pague a pena e, en consecuencia, entende que apoiar o plurilingüismo é unha medida desatinada, pódense poñer en dúbida tales ideas cun argumento moral, que daría lugar a un debate moral ou referido 
aos «dereitos». En xeral, esta argumentación goza de popularidade entre os xuristas, os teóricos políticos e, curiosamente, os sociolingüistas ${ }^{1}$.

- En segundo lugar, mesmo se se considera que o plurilingüismo é moralmente "correcto" e vén avalado polo discurso político e xurídico, pode rexeitarse por motivos de viabilidade, o cal daría lugar a un debate (basicamente) sociolingüístico centrado na dinámica das linguas, co cal a cuestión fundamental sería se tal dinámica constitúe un fenómeno en que pode influír a sociedade ou se, polo contrario, é totalmente alleo a calquera tipo de control social e, por tanto, se atopa fóra do ámbito das políticas públicas.

- En terceiro lugar, mesmo se se considera que o plurilingüismo é correcto en sentido moral e político, e ademais viable na práctica, pode rexeitarse argüíndo que supón desbaldir uns recursos que estarían mellor empregados para outros propósitos: por exemplo, en políticas sanitarias, de transporte ou educativas. Isto daría lugar a un terceiro debate, que desta vez versaría sobre a axeitada asignación duns recursos escasos (que é o que en economía denominariamos unha cuestión de «eficiencia da asignación»).

- En cuarto lugar, mesmo se se considera que o plurilingüismo é correcto en sentido moral e político e viable na práctica, e constitúe un bo fin ao que asignar uns recursos escasos, aínda xorde a pregunta de como repartir esta carga, que é o que en economía denominariamos unha cuestión de "xustiza distributiva».

Vexamos, pola nosa vez, os importantes problemas que se atopan no centro de cada un destes debates.

\section{a) O debate dos «dereitos»}

Moi a miúdo, os defensores do plurilingüismo adoptan argumentacións políticas de índole moral para xustificar a súa postura. De feito, os argumentos morais ou «baseados nos dereitos», nos cales adoitan invocarse os dereitos das minorías, probablemente sexan os máis empregados, e a cantidade de obras dedicadas aos dereitos lingüísticos (ou mesmo «dereitos humanos lingüísticos»)

\footnotetext{
${ }^{1}$ Véxase, por exemplo, Skutnabb-Kangas (2000).
} 
fai que pareza minúsculo o número de obras que tratan outros modos de abordar esta cuestión.

En sentido intrínseco, os argumentos morais non teñen nada de malo; máis ben ao contrario, calquera postura que adoptemos debería superar unhas probas éticas. No entanto, os argumentos morais teñen un punto feble importantísimo: que non adoitan impresionar a aqueles que non comparten as mesmas perspectivas morais. Pensemos, por exemplo, nun argumento como "é xusto e de dereito outorgarlles un recoñecemento a todas as comunidades lingüísticas que conforman o país e, xa que logo, debemos fomentar todas as súas linguas». Esta pode constituír unha posición totalmente coherente e unha postura eticamente sólida; porén, ao ser un argumento en esencia moral, pode caer en oídos xordos e con frecuencia vén sendo como predicar para os conversos. O problema radica en que non todo o mundo está xa convertido e non se pode simplemente pasar por alto as opinións daqueles que se opoñen ao plurilingüismo; ou, para sermos máis concretos, desde un punto de vista liberal resulta difícil limitarse a desbotar o parecer sincero das persoas que son contrarias ao plurilingüismo.

É máis, mesmo un argumento normativo e ben construído a prol do plurilingüismo pode rexeitarse e aducir que non é máis que a formulación dos gustos subxectivos do autor e, por tanto, non merece que se lle preste máis atención que á formulación, talvez menos sofisticada, duns gustos opostos.

Lembremos que na actualidade, e malia o grao de lexitimidade acadado, no groso do discurso público referente ao plurilingüismo e ás linguas minoritarias, os Estados non están obrigados por lei a garantir a supervivencia de todos os idiomas. A protección da lingua propia non está recoñecida como dereito individual absoluto nin vén consagrada en ningún instrumento internacional vinculante. Mentres que poucos se manifestarían hoxe en contra dunha intervención do Estado destinada a evitar expresións racistas, moitos aínda se opoñen a unha intervención a prol do plurilingüismo ou das linguas minoritarias; e non se pode simplemente desbotar os seus argumentos se se pretende influír na opinión pública. Hai que aceptar combatelos. Pero, como veremos máis adiante, pode deixarse á vista o punto feble analítico destes argumentos contrarios ao plurilingüismo sen recorrer a consideracións morais.

Está claro que o problema non se pode abordar neste mesmo plano, conxugando a teoría política, a filosofía política e, xaora, o dereito. Con todo - acaso 
porque proveño do ámbito das ciencias sociais, da economía, máis precisamente-, preferiría manterme á marxe deste debate porque hai outros vieiros. Desde unha perspectiva económica, o discurso do dereito é normativo por definición (a pesar de que os xuristas falan, en efecto, de "dereito positivo»); canto aos estudosos das ciencias políticas, estes recoñecen a orientación normativa do seu traballo (refírense, a este respecto, á «teoría política normativa»), e neste relatorio non pretendo introducirme no que xa é un terreo normativo trillado².

\section{b) O debate da viabilidade}

Dediquémoslle agora unhas palabras ao segundo dos debates, que xira arredor da viabilidade da promoción do plurilingüismo, ou á estabilidade deste a longo prazo.

Diversos autores, entre os que se contan senlleiros comentaristas do ámbito do dereito, da filosofía política ou mesmo das políticas lingüísticas (como Brian Barry, Philippe van Parijs ou Abram de Swaan) ${ }^{3}$, teñen refugado os labores de promoción ou mesmo de preservación da diversidade lingüística, e defenden que eses labores non son eficaces e que, chegado o caso, poderían ir en contra dos desexos das comunidades que falan as linguas en cuestión. Isto é, aparentemente, o que alega Edwards (1985), mais, en realidade, o que eu denomino argumento da «eficacia interna» só se refire á primeira parte deste: fagamos o que fixermos, as linguas veñen e van, algunhas están condenadas á extinción e nós gravitamos inexorablemente cara a un mundo lingüisticamente menos diverso.

En boa medida trátase dunha cuestión empírica que non temos tempo de abordar, pero mencionemos simplemente uns poucos datos que deberían alertarnos da complexidade dos procesos dos que estamos a falar.

Non nos deteñamos no eterno (e algo forzado) exemplo do renacer do hebreo. Porén, podemos observar que, nos últimos anos, a algunhas linguas que se infravaloraban por estaren moribundas vailles indo bastante ben, dadas as circunstancias - pensemos, por exemplo, no galés-, e que as condicións actuais resultan máis favorables do que foron en moito tempo, en vista non só da maior

\footnotetext{
${ }^{2}$ Véxanse Kymlicka (1995a, 1995b), May (2001), etc.

3 Véxanse Barry (2001), Van Parijs (2001, 2004) e De Swaan (2001).
} 
lexitimidade das linguas minoritarias, senón tamén dun renovado interese por esas linguas que semella ir da man da «globalización»". Así mesmo, procede advertir que o desenvolvemento tecnolóxico, lonxe de ser unha forza que só está ao servizo da difusión do inglés, fai visibles moitas máis linguas. Neste sentido, a proporción que lle corresponde ao inglés na internet vai en constante diminución, tanto se se cuantifica en función dos idiomas empregados nas páxinas web ou en función da lingua dos usuarios 5 . Ou, por engadir outro exemplo tirado do meu propio país, Suíza, onde temos catro linguas nacionais (francés, alemán, italiano e retorrománico), un estudo recente amosou que, ao contrario do que esperaban moitos, os contactos comerciais entre empresas situadas nesas diferentes rexións lingüísticas non se realizan en inglés, senón nos nosos idiomas nacionais.

A dinámica lingüística é, de certo, un tema complexo, mais existen abondosas probas (e multitude de anécdotas) que amosan que, malia o acelerado ritmo de extinción das linguas que contan con poucos falantes, a diversidade lingüística constitúe unha realidade actual que non é antitética ao desenvolvemento tecnolóxico e económico, e que se pode reforzar mediante políticas públicas... se hai vontade.

\section{c) O debate da eficiencia da asignación}

Agora ben, de verdade temos vontade de facelo? Isto lévanos ao terceiro debate. Aínda que os dous temas anteriores se resolveron a favor do plurilingüismo (noutras palabras, "é correcto en sentido moral e político» e "resulta viable na práctica»), moitos sosterán que é unha mala idea e con ela se fará un uso inadecuado duns recursos escasos. Esta idea goza de gran popularidade entre os membros da miña disciplina (a economía, é dicir, se é que se preocupan algo por cuestións lingüísticas). Ao respecto, Jones (2000) presentou unha nova formulación, que comeza coa afirmación de que a humanidade precisa dun «idioma común». En si mesmo, este é un punto de partida lexítimo para elaborar unha argumentación científica, mais Jones vai caendo na estratexia de infravalorar os

\footnotetext{
${ }^{4}$ Poida que ese paradoxo só o sexa en aparencia; véxase Grin e Rossiaud (1999).

${ }^{5}$ Véxase http://www.internetworldstats.com/stats7.htm (última consulta: 24 de febreiro de 2007).
} 
esforzos de promoción da diversidade lingüística, a cal, por lóxica, é unha cuestión diferente, pero ese propio paso da unha á outra indica, na miña opinión, as intencións de supremacía que teñen moitos dos que avogan por un idioma mundial (véxase Phillipson, 2003).

$\mathrm{O}$ argumento é ben coñecido e non é que se poida precisamente rebatelo con razóns morais, ou, dito doutro xeito, as consideracións morais ou referidas aos dereitos simplemente non proceden porque aqueles que coidan que resulta desatinado asignarlle recursos ao plurilingüismo non adoitan crer que haxa xustificación para a supervivencia das linguas en xeral, por non falar de que haxa «dereito» (e as súas opinións subxectivas non son menos válidas que as dos defensores do plurilingüismo). Eles levan a cuestión a outro plano, que é este: "Cando se trata do benestar da sociedade no seu conxunto, ten sentido destinar recursos ao plurilingüismo?». E a súa resposta é negativa.

Moi logo volverei a este punto (e dedicareille un apartado enteiro) porque entendo que é aquí onde se conxugan elementos clave para o futuro da diversidade lingüística. Polo momento, imos retornar brevemente ao cuarto debate, que non se centra na asignación de recursos, senón na súa distribución, e, así, falamos de xustiza ou equidade distributiva.

\section{d) O debate sobre a xustiza distributiva}

Supoñamos agora que o plurilingüismo goza de recoñecemento en canto moralmente correcto, viable na práctica e un bo destino para os recursos da sociedade, igual que tamén resulta atinado optar por protexer o medio. Malia todo, aínda falta determinar quen debería pagar, ou, máis precisamente, como se deberían repartir os custos que comportan a protección e a promoción do plurilingüismo.

A dimensión do problema fai que o groso dos recursos necesarios se lles poida aplicar a persoas que probablemente non se vaian beneficiar de modo directo desa iniciativa (ou que cren que non se van beneficiar). Daquela, pode rexeitarse a promoción da diversidade lingüística e argüír que comporta unha redistribución inxustificada.

A redistribución constitúe un punto clave de todas as políticas públicas. Considérese, por exemplo, o ensino universitario gratuíto, ou con taxas reduci- 
das (que segue a ser a norma en Suíza, Alemaña, Francia, España, Bélxica, os Países Baixos, Austria e por toda Escandinavia, por exemplo). Pode rexeitarse porque comporta que a clase media-alta (que envía os fillos á universidade) recibe subsidios de toda a masa de contribuíntes e, de maneira implícita, que os que son relativamente ricos reciben unha transferencia dos que son relativamente pobres.

Do mesmo xeito, o debate referido aos pros e aos contras do plurilingüismo pode centrarse nesa implícita redistribución de recursos e na pertinencia de tal transferencia. En certo modo, esta cuestión lévanos de novo ao problema normativo do principio (é dicir, ao debate «moral»), mais desde un ángulo totalmente diferente, no cal non entra en xogo a noción de dereitos indiscutibles, senón a de xustiza.

Trátase dun aspecto das políticas lingüísticas que se explorou relativamente pouco (véxanse, con todo, Pool, 1991; Grin, 2005; De Briey e Van Parijs, 2002), por veces moi técnico e que, infelizmente, vou ter que me abster de tratar no resto do artigo. Digamos, simplemente, que este aspecto non presenta ningún problema fundamental, porque, en principio, sempre se poden facer axustes para garantir que, mediante esas transferencias entre iniciais gañadores e perdedores, ninguén se vexa prexudicado por medida ningunha; porén, si xurdirían notables problemas de aplicación.

\section{PROBLEMAS DE ASIGNACIÓN: DIVERSIDADE LINGÜÍSTICA E VALOR ECONÓMICO}

Pasemos agora a considerarmos máis detidamente o terceiro dos debates: habería que asignar recursos (entre eles, ingresos fiscais) para garantir o plurilingüismo na sociedade?

Máis unha vez, o problema ten que descomporse en dúas preguntas independentes: unha é se, polo resultado, paga a pena investir eses recursos; a outra, se tal investimento é competencia do Estado ou se non habería que deixalo para a iniciativa privada. Con todo, e como veremos cando nos desviemos un pouco polos vieiros da teoría económica, estas dúas preguntas están estreitamente relacionadas. 
Para entendermos este punto, resultaranos de axuda estudar os diversos aspectos do problema «da asignación». Observemos, primeiramente, que a cuestión varía moito en función de se nos preocupamos polo plurilingüismo «no sentido absoluto" (é dicir, cando o contrafactual é a unidade lingüística no mundo, ou unilingüismo) ou no "continxente», sentido no cal ponderamos o valor de levarmos a cabo unha ou máis estratexias "plurilingüistas» nunha continxencia dada, a saber: que o mundo sexa plurilingüe. En diante ímonos centrar nesta última situación, na cal podemos considerar tres niveis avaliativos:

$\left.1^{\circ}\right)$ os beneficios e os custos que se derivan para o individuo, e que comprenden os seguintes elementos: 1) efectos simbólicos (ou «alleos ao mercado»), que ata agora practicamente non se teñen avaliado en termos cuantitativos, e 2) diferenciais de vantaxes en favor de persoas que posúen determinadas habilidades plurilingües (diferenciais que adoitan denominarse «índices de rendibilidade privada», expresión que resulta cómoda de empregar, mais que non é analiticamente correcta ao cento por cento);

$2^{\circ}$ ) beneficios e custos cuantificados á escala social, tendo en conta que se invisten recursos no ensino e na aprendizaxe de linguas estranxeiras (sobre todo por medio do sistema educativo); o valor neto resultante calcúlase polo xeral mediante «dereitos sociais de retorno sobre o investimento» (que, en termos técnicos, constitúen verdadeiros índices de rendibilidade);

3o) beneficios e custos cuantificados á escala da economía no seu conxunto, na cal se tratan as habilidades lingüísticas como factores de produción (é dicir, como insumos dun proceso de produción global visto desde a perspectiva macroeconómica); o valor resultante exprésase habitualmente como porcentaxe do PIB (produto interior bruto).

Nos últimos anos, cobraron gran forza as argumentacións referidas ao plurilingüismo continxente, no sentido de que en xeral pode amosarse que o seu valor de mercado é positivo. Para isto cómpren moitos datos e, nestes momentos, son relativamente poucos os casos (por exemplo, Suíza e o Quebec) en que se efectuou algún cálculo (Grin, Sfreddo e Vaillancourt, 2010); con todo, malia que se pode esperar que os índices privados e sociais de rendibilidade sexan menores en países menos plurilingües, o máis probable é que, aínda así, sigan a ser positivos. Se se teñen en conta os beneficios alleos ao mercado (noutras palabras, o aproveitamento directo que se deriva do coñecemento ou do uso doutras 
linguas, igual que se pode tirar proveito do contacto intercultural en xeral), os efectos que isto comportará para a nosa conclusión, de habelos, irán no sentido de ratificala.

A pesar de que comezan a facerse cálculos nun abano cada vez maior de contextos económicos, aínda non se sabe moito sobre os procesos subxacentes á creación de valor e, por iso, segue a pagar a pena deterse a analizar unha serie de supostos: por exemplo, se o plurilingüismo individual se atopa en correlación coa creatividade e, xa que logo, se a creatividade podería ser a explicación dunha maior produtividade, na cal, pola súa vez, se cifraría a razón da aparición de niveis estatisticamente significativos nos índices privados e sociais de rendemento por habilidades lingüísticas.

No entanto, o debate adoita pasar da noción do plurilingüismo continxente á do absoluto, e iso sen que os participantes no debate sexan conscientes. Examinemos, pois, a cuestión do plurilingüismo absoluto: para dicilo claramente, non nos iría mellor a todos se só houbese un idioma na Terra? A pregunta paréceme ridícula e espero que aos meus lectores tamén, mais lémbrese que hai moitos que efectivamente pensan así..., sobre todo cando a única lingua que se postula para a supervivencia resulta ser (sorpresa!) a propia.

Este último aspecto está intimamente relacionado co problema de que función desempeña o Estado nas cuestións lingüísticas. Así, un podería argumentar, certamente (seguindo unha ideoloxía típica do laissez faire), que o Goberno non debería intervir e que os máximos beneficios para o benestar se derivarán das accións non coordinadas das persoas (físicas e xurídicas, así como entidades do sector terciario), que permitirán que os mecanismos do mercado regulen, por así dicilo, a "produción» da diversidade: pois, se a diversidade é algo que desexe a xente, haberá algunha demanda e "producirase» en grao suficiente. Se non se "produce» moita (ou ningunha) diversidade, será porque a sociedade non a quere e - de modo implícito- non ten problema en funcionar cun só idioma.

Esta liña argumental resulta bastante crible cando falamos de bens «sinxelos», como tomates, televisores ou pneumáticos. Infelizmente, non vale para produtos máis complexos, como o ensino, a sanidade ou o medio; nin, xaora, para os idiomas en canto compoñentes do noso contorno lingüístico.

Mesmo as correntes económicas dominantes recoñecen que existen algúns casos en que o mercado non abonda, coñecidos como «eivas de mercado». 
Cando se dan, a interacción desordenada entre a oferta e a demanda ten como consecuencia un nivel inadecuado de produción dun determinado ben, e é «inadecuado», «demasiado» ou «demasiado pouco».

Segundo a teoría económica, existen basicamente seis elementos xeradores de eivas de mercado ${ }^{6}$, que aquí non imos entrar a tratar. Con todo, fica bastante claro que, no caso da diversidade lingüística, estas eivas xorden por máis dunha desas seis canles, unha das cales reviste especial importancia: a natureza da diversidade, ou das linguas que a compoñen, como «ben público».

O que se intúe aquí é o seguinte: a diversidade lingüística comparte moitas características coa biodiversidade, que xeralmente se recoñece como un tipo de ben público (e permítaseme engadir, de paso, que este paralelismo se pode establecer sen recorrer a discutibles metáforas biolóxicas). De xeito moi semellante ao que ocorre coa calidade do aire e da auga, as linguas constitúen un medio que presenta as características básicas dos «bens públicos», que o mercado, se se deixa só, non fornecerá en cantidade suficiente. Isto aplícase, en particular, ás linguas menores e habitualmente non dominantes. É importante sinalar que, por estes motivos, pode defenderse o intervencionismo estatal na protección da diversidade lingüística non con argumentos políticos nin apelando aos dereitos humanos ou aos das minorías, senón coa teoría económica.

No entanto, os lectores observarían xa que toda a liña argumental se elabora arredor da suposición de que a diversidade lingüística é, en esencia, un ben e non un mal. Hai quen está disposto a soster que a diversidade é intrinsecamente mala, igual que a contaminación do aire e da auga é mala (polo menos para a maioría das persoas), mais, en xeral, somos remisos a afirmar que a diversidade lingüística sexa un mal per se. Xa que logo, se non estamos dispostos a facer tal afirmación (que despois habería que defender con argumentos convincentes), de aí dedúcese que non temos reparo en recoñecer que, en igualdade de condicións, a diversidade lingüística é un ben.

Normalmente a postura que lles serve de colchón aos inimigos do plurilingüismo é a de dicir, daquela, que «si, todo estupendo, mais demasiado caro». Pero éo en realidade? Velaquí a cuestión á que retornaremos na conclusión deste relatorio.

\footnotetext{
${ }^{6}$ Para consultar un tratamento pormenorizado destas cuestións véxase calquera manual de economía pública.
} 


\section{PAGA A PENA FACER ESFORZOS A PROL DA DIVERSIDADE LINGÜÍSTICA? DOS BENEFICIOS AOS CUSTOS}

Todo argumento asignativo en favor do plurilingüismo (noutras palabras, que asignarlle fondos á promoción do plurilingüismo constitúe un uso eficiente dos recursos) deberá, obviamente, ofrecer probas de que os recursos investidos nel estarán ben empregados, o que significa que os beneficios resultantes serán maiores que os custos.

Malia que unha avaliación conxunta dos custos e dos beneficios nos levaría demasiado lonxe, é lóxico que vaia xurdir unha diferenza positiva entre uns e outros se os beneficios son altos, ou ben se os custos son baixos.

Avaliar os beneficios adoita ser o máis difícil, polo que me vou limitar a repetir que habería que estudar a diversidade lingüística cos mesmos ollos con que se estuda o noso medio natural. Cada vez máis, recoñécese que unha maior calidade ambiental redunda nunha maior calidade de vida, mesmo se a índole deses beneficios é difícil de aprehender. Así, é un beneficio que unha paisaxe non estragada resulte agradable á vista, mais por que aceptamos incorrer nos custos que correspondan, se non é porque estamos dispostos a dedicar uns recursos escasos a unha noción complexa, e talvez imposible de definir, como é a de "calidade»? O mesmo pode dicirse do noso contorno lingüístico: moitos estarían de acordo en que existe unha correlación positiva entre a diversidade dese contorno e a nosa calidade de vida.

Malia que esta opinión, que persoalmente subscribo, pode ir gañando terreo, adoito segue a ser difícil de vender. No entanto, resulta máis doado centrarse na outra cara da moeda e amosar que, aínda que non esteamos seguros de todo da cantidade de beneficios que xera a promoción das linguas minoritarias, os seus custos son bastante baixos; moito máis, en calquera caso, do que parece supor un gran número de comentaristas, que normalmente non se apoian en moitas probas ou en ningunha en absoluto.

É certo que, nestes momentos, o volume de evidencias de que dispomos acerca dos custos da promoción das linguas minoritarias é reducido. Con todo, polo xeral apunta na dirección duns custos moderados. Para resolver este aspecto voume limitar a presentar un exemplo: o de pasar dun sistema educativo monolingüe (no que só haxa un idioma dominante $\mathrm{Y}$ ) a outro bilingüe $(\mathrm{X}+\mathrm{Y})$, no cal ambas as linguas sirvan de medios de instrución. 
Como punto de partida global debemos lembrar que o Estado ten a responsabilidade xeral de fornecer (e financiar) o ensino obrigatorio. A esta responsabilidade van aparellados determinados custos; de aí que o prezo real do ensino bilingüe sexa o custo que comporta por riba do sistema alternativo, o ensino monolingüe.

Ténense feito cálculos no caso da educación en éuscaro no País Vasco, ou en linguas indíxenas (o maia, en particular) en Guatemala. En tales casos, hai estudos independentes que chegan a uns resultados sorprendentemente aproximados, todos no rango do 4 ou o $5 \%$ de semellanza. É probable que estas cifras representen cálculos no seu extremo superior, por mor da evolución a longo prazo dalgúns dos termos que entran neles (sobre todo a formación dos docentes, destinada a permitirlles ensinar nunha lingua non dominante).

É posible (e, de feito, necesario) que se produzan máis avances neste sentido, pero resulta sumamente plausible que, ao pasar dun sistema de ensino monolingüe a outro bilingüe, os alumnos poidan recibir unha educación nun idioma que entendan ben, e non nun que comprendan mal, o cal xerará beneficios adicionais.

Esta conclusión non pode ser máis que temporal, dado que aínda queda un considerable traballo teórico e empírico por facer para que poidamos saber máis verbo do que custa promover o plurilingüismo e garantilo a longo prazo. Non obstante, baseándonos no que xa sabemos, podemos dicir que, de certo, o plurilingüismo está economicamente ao noso alcance.

Con isto xa temos algo para responder á pregunta «Plurilingüismo? Por que preocuparse?». A contestación lóxica será simplemente: «Por que? Porque é moralmente correcto, tecnicamente viable... e o investimento paga a pena». 


\section{BIBLIOGRAFÍA}

BARrY, B.: Culture and Equality: An Egalitarian Critique of Multiculturalism, Cambridge, Mass., Harvard University Press, 2001.

BrIey, L. de e Ph. VAN PARIJS: «La justice linguistique comme justice coopérative», Philosophie Économique 5 (1), 2002, pp. 5-37.

EDWARDS, J.: Language, Society and Identity, Oxford, Basil Blackwell, 1985.

GRIN, F.: L'enseignement des langues étrangères comme politique publique, Paris, Haut Conseil de l'Évaluation de l'École, 2005a, http://cisad.adc.education.fr/hcee.

- "The economics of language policy implementation: identifying and measuring costs», en N. ALEXANDER (ed.), Mother Tongue-based Bilingual Education in Southern Africa. The Dynamics of Implementation, Cape Town, PRAESA, 2005b, pp. 11-25.

- e J. Rossiaud: «Mondialisation, processus marchands et dynamique des langues ", en S. ABOU (ed.), Uniformisation ou différenciation des modèles culturels, París, AUPELF-UREF (Col. «L'Actualité scientifique») et Beyrouth, Université Saint-Joseph, 1999, pp. 113-142.

- C. Sfreddo e F. Vaillancourt: The Economics of the Multilingual Workplace, Londres, Routledge, 2010.

— e F. VaillancourT: «The Economics of Multilingualism: Overview of the Literature and Analytical Framework», en W. GraBE (ed.), Multilingualism and Multilingual Communities (ARAL XVII), Cambridge, Mass., Cambridge University Press, 1997, pp. 43-65.

JONES, E.: «The case for a shared world language», en M. CASSON e A. GODLEY (eds.), Cultural Factors in Economic Growth, Berlín, Springer, 2000, pp. 210-235.

KyмLICKA, W.: Multicultural Citizenship. A Liberal Theory of Minority Rights, Oxford, Clarendon Press, $1995 \mathrm{a}$.

— (ed.): The Rights of Minority Cultures, Oxford, Oxford University Press, $1995 \mathrm{~b}$.

MAY, S.: Language and Minority Rights, Harlow, Pearson, 2001.

PARIJS, Ph. van: «Le rez-de-chaussée du monde. Sur les implications socio-économiques de la mondialisation linguistique», en J. Delcourt e Ph. DE WoOt (dirs.), Les défis de la globalisation. Babel ou Pentecôte?, Louvain-la-Neuve, Presses Universitaires de Louvain, 2001, pp. 479-500.

— «Europe’s Linguistic Challenge», Archives Européennes de Sociologie, XLV (1), 2004, pp. 113-154.

Phillipson, R.: English-Only Europe?, Londres, Routledge, 2003.

Pool, J.: «The Official Language Problem», American Political Science Review, 85, 1991, pp. 495-514.

SkUtnabb-Kangas, T.: Linguistic Genocide in Education, Nova York, Lawrence Erlbaum, 2000.

THIEBERGer, N.: «Language Maintenance: Why Bother?», Multilingua, 9, 1990, pp. 333-358. 